\title{
Female Oviposition Decisions and Their Impact on Progeny Life-History Traits
}

\author{
Satu Paukku • Janne S. Kotiaho
}

Revised: 22 April 2008 / Accepted: 30 July 2008 /

Published online: 20 August 2008

(C) The Author(s) 2008. This article is published with open access at Springerlink.com

\begin{abstract}
An important factor affecting the life-history of an organism is parental investment in reproduction: reproductive decisions are almost invariably costly. Therefore, reproductive decisions should be beneficial in terms of increased offspring number or fitness. For example, egg laying decisions in many insects can influence resource availability of the offspring through changes in the larval density, and resource availability will have effects on many life-history traits. Here we studied whether female reproductive decisions affect offspring fitness in Callosobruchus maculatus seed beetles. Females laid more eggs on black-eye beans than on mung beans. However, when the difference in the surface area of the beans was accounted for, the number of eggs was not higher in black-eye beans. This together with the poisson distribution of eggs on each of the bean types suggests that females tend to lay their eggs randomly. We found that development time was longer, larval mortality lower and adult survival higher in black-eye beans. We also found interactions between bean type and larval density on size of the offspring such that in mung beans the emergence mass and pronotum width decreased with increasing larval density, but in black-eye beans larval density did not affect the size measures. We conclude that when there is a risk that larval denisty will become high within a bean and there is variable resources available, there exist clear benefits that females might obtain by choosing black-eye beans as a resource for their offspring. However, in contrast to many earlier studies, our results suggest that females may not be making any active oviposition decisions. Therefore, to unequivocally determine whether females do capitalise the potential benefits by active decision making, some further experimentation is required.
\end{abstract}

Keywords Callosobruchus maculatus · fitness · egg laying · larval density · oviposition · Vigna

S. Paukku $(\bowtie) \cdot$ J. S. Kotiaho

Centre of Excellence in Evolutionary Research, Department of Biological and Environmental Science, University of Jyväskylä, P.O. Box 35, 40014 Jyväskylä, Finland e-mail: satupau@bytl.jyu.fi 


\section{Introduction}

Many factors affect the life history of an organism. One important factor is parental investment (Trivers 1972); it is well founded that reproductive decisions should be almost invariably costly for the breeding adult (e.g. Williams 1966; Partridge and Harvey 1985; Bell and Koufopanou 1986; Kotiaho 2001; Paukku and Kotiaho 2005). Moreover, parents' reproductive decisions are likely to strongly affect the fitness of the offspring because these decisions determine the environmental quality for the life of the offspring. These decisions may occur e.g. in brooding, nesting or feeding when there is direct contact with offspring, but particularly in insects in the form of egg laying decisions that involve choosing a resource or modifying the development environment of the offspring (Clutton-Brock 1991).

The egg laying decisions of a female may benefit her offspring in several ways. In insects, two broad decisions that a female must make are the laying mode i.e. to lay singly or in clusters, and the selection of the laying substrate. In general, females should select an oviposition mode and substrate that maximizes their fitness (Sherratt and Church 1994). For example, female Iphiseius degenerans mites lay eggs into clusters to better protect them from egg predation and larval cannibalism (Faraji et al. 2002). Similarily, Trichoprosopon digitatum mosquitoes lay eggs during a short time interval in the same place because it results in similar sized larvae, preventing larval cannibalism (Sherrat and Church 1994). In some species females lay in places where suitable nutrition is abundantly available or they may actively gather resources into which they subsequently oviposit (e.g. Krebs and Davies 1997; Gullan and Cranston 2000; Hunt et al. 2002; Janz et al. 2005). When several eggs are laid on the same resource, larval density will increase. If larvae have to compete over resources, it may have an impact on many important life-history traits, such as development time, adult size, adult longevity, and consequently fitness (e.g. Colegrave 1993; Horng 1997; Agnew et al. 2000).

In the absence of haplodiploid sex determination, in which there is a great deal of maternal control of sex ratio (e.g. Gullan and Cranston 2000; Tomkins et al. 2001), adaptive sex ratio bias has occasionally been reported. For example, in the Seychelles warblers Acrocephalus sechellensis more females are produced in high-quality environment and more males in low-quality environment (Komdeur 2003). Sex ratio bias in the progeny of an individual or population can also be the consequence of manipulation by a parasite e.g. Wolbachia (e.g. Gullan and Cranston 2000; Stouthamer et al. 2001), and as such is not necessarily an adaptive sex ratio change for the host.

Here we report results from three experiments. First, we conducted an experiment to investigate whether females prefer one of the two host types, smaller mung bean (Vigna radiata) or larger black-eye bean (Vigna unguiculata), as an oviposition substrate. In addition to the type of the bean, we, unlike many other earlier studies of host preference (e.g. Guedes et al. 2003; Kawecki and Mery 2003; but see: Messina and Mitchell 1989; Messina 2004) also considered that the beans of different types have a different surface area. This is important as surface area of the bean has an influence on the null hypothesis against which female oviposition preferences should be tested. Second, we conducted an experiment to investigate whether the host species or the larval density affects the life-history of the beetles. Finally, we studied whether there is adaptive sex-ratio manipulation by females in relation to host species or the risk of high larval density. 


\section{Methods}

\section{Study Species}

Callosobruchus maculatus (Fabricius, Bruchidae) seed beetle is a common postharvest pest of stored legumes in tropical and subtropical regions. The species uses Vigna-beans, e.g. black-eye beans ( $V$. unguiculata, L., Fabaceae, also known as cowpea) and mung beans ( $V$. radiata, L. Fabaceae) as nutrition during their larval stage. C. maculatus beetles develop from egg to adult in 25-40 days, depending on environmental factors, such as temperature. Females lay eggs on beans, and 45 days later, first instar larvae burrow themselves inside the bean (Fox 1993; Fox and Tatar 1994). Larvae feed and develop within a single bean until they emerge as adults. Adults do not require any nutrition or water to reproduce. Their suitability to laboratory conditions has made them a model system in many life-history studies (e.g. Fox 1993; Fox and Tatar 1994).

Our population of $C$. maculatus originates from Brazil and was brought into the laboratory initially in 1982, and has been maintained in University of Jyväskylä since September 2000. Population is cultured in containers of $0.91(95 \times 95 \times 100 \mathrm{~mm})$ with about $70-80 \mathrm{~g}$ of dried black-eyed beans in each container. During the experiment all animals were kept individually in pierced Eppendorf tubes of $1.5 \mathrm{ml}$. Cultures and animals in the experiment were kept at $20^{\circ} \mathrm{C}$ in the laboratory, where light conditions were 15L:9D.

\section{Oviposition Preference}

In the first experiment, female oviposition preference was studied between two bean types. To study this, 100 virgin $C$. maculatus females were mated once each with a virgin male. Both females and males were 0-2 days old when mated. After mating, females were placed individually into the experimental containers to lay their eggs. Each container $(\varnothing 45 \mathrm{~mm} \times 65 \mathrm{~mm})$ contained 50 mung beans and 50 black-eye beans. After the death of the females, number of eggs on each bean was counted. The same procedure was repeated for all 100 containers.

The surface area of black-eye beans was calculated with formula of surface area of an ellipsoid:

$$
2 \pi\left(c^{2}+\frac{b c^{2}}{\sqrt{a^{2}-c^{2}}} \operatorname{Elliptic} E(\theta, m)+b \sqrt{a^{2}-c^{2}} \text { Elliptic } F(\theta, m)\right)
$$

in which $a, b$ and $c$ are semi-axes

$$
m=\frac{a^{2}\left(b^{2}-c^{2}\right)}{b^{2}\left(a^{2}-c^{2}\right)} ; \theta=\operatorname{ArcSin}\left[\sqrt{1-\frac{c^{2}}{a^{2}}}\right] / a \geq b \geq c
$$

The surface area of mung beans was calculated with formula of surface area of cylinder:

$$
2 \pi r h+2 \pi r^{2}
$$

in which $r=$ radius and $\mathrm{i}=$ height. 


\section{Larval Density}

In the second experiment, the effect of bean type and larval density was studied on several life-history traits: development time (i.e. number of days from the date the egg was laid to the date the adult emerged), larval mortality (i.e. number of eggs laid minus number of adults emerged), emergence mass (adult mass was weighed at the day of emergence), relative emergence mass (i.e. emergence mass controlled for pronotum width) and adult longevity. The experiment was started by collecting mung beans and black-eye beans with one, three or five eggs from our beetle culture. 40 beans was allocated to each combination, resulting a total of 240 beans. Each bean was placed individually in a pierced Eppendorf tube of $1.5 \mathrm{ml}$. Longevity was checked daily.

\section{Adaptive Sex-ratio Manipulation by Females}

Motivated by our findings in the larval density experiment, the third experiment was conducted. This one was a formal experiment on the possible adaptive sex-ratio manipulation by females. To determine whether females are able to determine the sex of their offspring depending on the risk of high larval density, the female perception of larval density was manipulated. First, females were given fresh (unused by beetles) mung beans or black-eye beans to lay eggs on. From these, 200 mung beans and 200 black-eye beans that had a single egg laid on them were collected. Next, 200 mung beans and 200 black-eye beans with four eggs on each were collected from the culture. All four eggs were laid within the previous 24 hours. Each of the four eggs on each of the beans was marked by pencilling a circle around them. These beans with one or four eggs were then offered to females. After each female had laid one egg on the bean the female was removed and the previous eggs were scraped off before the experimental eggs hatched. These are beans in which females lay eggs perceiving low or high larval density. Each bean was placed in a pierced Eppendorf tube of $1.5 \mathrm{ml}$. Piercing allowed gaseous exchange. At the emergence of the adults the adult sex was determined. This design was used to determine whether females determine the sex of their offspring depending on the risk of larval density.

\section{Results}

\section{Oviposition Preference}

Females laid significantly more often on black-eye beans than on mung beans, the number of beans on which each female laid was $22.6 \pm 9.7$ (mean \pm SD) vs. 17.2 \pm 6.4 (mean $\pm \mathrm{SD}$ ) respectively (paired samples $t$-test, $t_{99}=6.06, P<0.001$ ). In addition, the number of eggs laid on black-eye beans (i.e. the number of eggs on the 50 available beans) was greater than that on mung beans (31.2 \pm 15.8 (mean \pm SD) vs. $20.4 \pm 7.9$ (mean $\pm \mathrm{SD}$ ) respectively, paired samples $t$-test, $\left.t_{99}=7.40, P<0.001\right)$. Similarly, the density of eggs on the beans that had at least one egg was higher on black-eye beans than on mung beans $(1.33 \pm 0.20$ (mean \pm SD) vs. $1.20 \pm 0.34$ (mean \pm SD) eggs per bean respectively, paired samples $t$-test, $\left.t_{99}=3.57, P<0.001\right)$. 
However, the two bean types differ in size so they have a different surface area and a different volume. The surface area of black-eye beans is 1.6 times greater than that of mung beans $\left(1.60 \pm 0.17 \mathrm{~cm}^{2}\right.$ (mean \pm SD) vs. $0.98 \pm 0.08 \mathrm{~cm}^{2}$ (mean $\pm \mathrm{SD}$ ) respectively) and the volume of black-eye beans is 5.0 times greater than that of mung beans $\left(177.6 \pm 33.5 \mathrm{~mm}^{3}\right.$ (mean $\pm \mathrm{SD}$ ) vs. $35.7 \pm 3.0 \mathrm{~mm}^{3}$ (mean $\pm \mathrm{SD}$ ) respectively). The number of eggs laid per unit surface area of beans is 1.3 times higher for mung beans $\left(0.51 \mathrm{eggs} / \mathrm{cm}^{2}\right)$ than for black eye beans $\left(0.39 \mathrm{eggs} / \mathrm{cm}^{2}\right)$, while the number of eggs per unit volume of beans is 4.5 times higher for mung beans $\left(3.4 \mathrm{eggs} / 100 \mathrm{~mm}^{3}\right)$ than for black eye-beans $\left(0.7 \mathrm{eggs} / 100 \mathrm{~mm}^{3}\right)$. Taken together, it seems that females lay more eggs and more often on black-eye beans than on mung beans, but when the difference in the surface area of the beans was accounted for, the number of eggs per surface area was not higher in black-eye beans.

The distribution of eggs on both types of beans is depicted in the Fig. 1. Overall, there was a difference in the distribution of the eggs between the two bean species: eggs were laid more evenly on black-eye beans than mung beans (KolmogorovSmirnov two-sample test $Z=5.45, N_{\text {mung }}=4987, N_{\text {black-eye }}=4974, P<0.001$, Fig. 1). However, the distribution of eggs on black-eye or on mung beans did not deviate from a Poisson distribution (Kolmogorov-Smirnov one-sample test, mung beans: $Z=0.43$, $N=4987, P=0.993$; black-eye beans: $Z=0.92, N=4974, P=0.367$ ), but both did deviate from a uniform distribution (Kolmogorov-Smirnov one-sample test, mung beans: $Z=62.3, N=4987, P<0.001$; black-eye beans: $Z=49.05, N=4974, P<0.001$ ).

\section{Effects of Larval Density}

\section{Emergence Mass, Pronotum Width and Relative Emergence Mass}

Population parameters on the emergence mass and pronotum width are presented in Tables 1 and 2. We began the analysis on the effects of larval density with a fully saturated model and continued by stepwise removal of all non-significant interaction terms starting from the highest order interactions. The final model included an interaction between bean type and number of eggs per bean and a main effect of sex on both emergence mass and pronotum width (Tables 3 and 4 respectively). From the Fig. 2 we can see that in mung beans the emergence mass decreased with increasing larval density, but in black-eye beans larval density did not affect the emergence mass.

Fig. 1 Percentages of beans with different number of eggs. Squares and solid line represent mung beans and dots with broken line indicate black-eye beans.

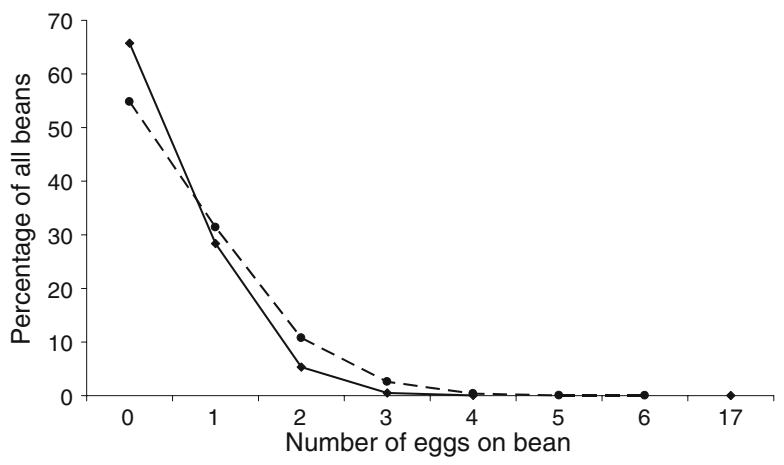


Table 1 Population Parameters on Emergence Mass (mg)

\begin{tabular}{|c|c|c|c|c|c|c|c|c|}
\hline \multirow[t]{3}{*}{ No. of eggs } & \multicolumn{4}{|l|}{ Males } & \multicolumn{4}{|c|}{ Females } \\
\hline & \multicolumn{2}{|l|}{ Mung } & \multicolumn{2}{|c|}{ Black-eye } & \multicolumn{2}{|l|}{ Mung } & \multicolumn{2}{|c|}{ Black-eye } \\
\hline & Mean & $\mathrm{SD}$ & Mean & SD & Mean & SD & Mean & $\mathrm{SD}$ \\
\hline 1 & 5.09 & 0.63 & 4.73 & 0.75 & 5.99 & 0.74 & 5.67 & 0.60 \\
\hline 3 & 4.63 & 0.82 & 5.13 & 0.66 & 5.38 & 0.93 & 5.97 & 0.79 \\
\hline 5 & 3.80 & 1.01 & 4.78 & 0.76 & 4.33 & 1.40 & 5.78 & 0.88 \\
\hline
\end{tabular}

Table 2 Population Parameters on Pronotum Width (mm)

\begin{tabular}{|c|c|c|c|c|c|c|c|c|}
\hline \multirow[t]{3}{*}{ No. of eggs } & \multicolumn{4}{|l|}{ Males } & \multicolumn{4}{|c|}{ Females } \\
\hline & \multicolumn{2}{|l|}{ Mung } & \multicolumn{2}{|c|}{ Black-eye } & \multicolumn{2}{|l|}{ Mung } & \multicolumn{2}{|c|}{ Black-eye } \\
\hline & Mean & $\mathrm{SD}$ & Mean & SD & Mean & SD & Mean & $\mathrm{SD}$ \\
\hline 1 & 1.20 & 0.09 & 1.20 & 0.06 & 1.28 & 0.06 & 1.26 & 0.06 \\
\hline 3 & 1.21 & 0.07 & 1.25 & 0.08 & 1.25 & 0.07 & 1.26 & 0.07 \\
\hline 5 & 1.12 & 0.11 & 1.23 & 0.07 & 1.15 & 0.12 & 1.27 & 0.08 \\
\hline
\end{tabular}

Table 3 Analysis of Variance on Emergence Mass

\begin{tabular}{lrrrrr}
\hline Source & \multicolumn{1}{l}{$S S$} & d.f. & $M S$ & \multicolumn{1}{l}{$F$} & $P$ \\
\hline Sex & 67.78 & 1 & 67.78 & 83.97 & $<0.001$ \\
Bean type & 16.26 & 1 & 16.26 & 20.15 & $<0.001$ \\
Number of eggs per bean & 40.19 & 2 & 20.10 & 24.90 & $<0.001$ \\
Bean type $\times$ number of eggs per bean & 29.31 & 2 & 14.65 & 18.15 & $<0.001$ \\
Error & 342.24 & 424 & 0.81 & & \\
\hline
\end{tabular}

Table 4 Analysis of Variance on Pronotum Width

\begin{tabular}{lrrrrr}
\hline Source & \multicolumn{1}{l}{ SS } & d.f. & $M S$ & $F$ & $P$ \\
\hline Sex & 202.79 & 1 & 202.79 & 18.19 & $<0.001$ \\
Bean type & 184.56 & 1 & 184.56 & 16.56 & $<0.001$ \\
Number of eggs & 417.80 & 2 & 208.90 & 18.74 & $<0.001$ \\
Bean type $\times$ number of eggs & 492.37 & 2 & 246.19 & 22.09 & $<0.001$ \\
Error & 4715.28 & 423 & 0.81 & & \\
\hline
\end{tabular}



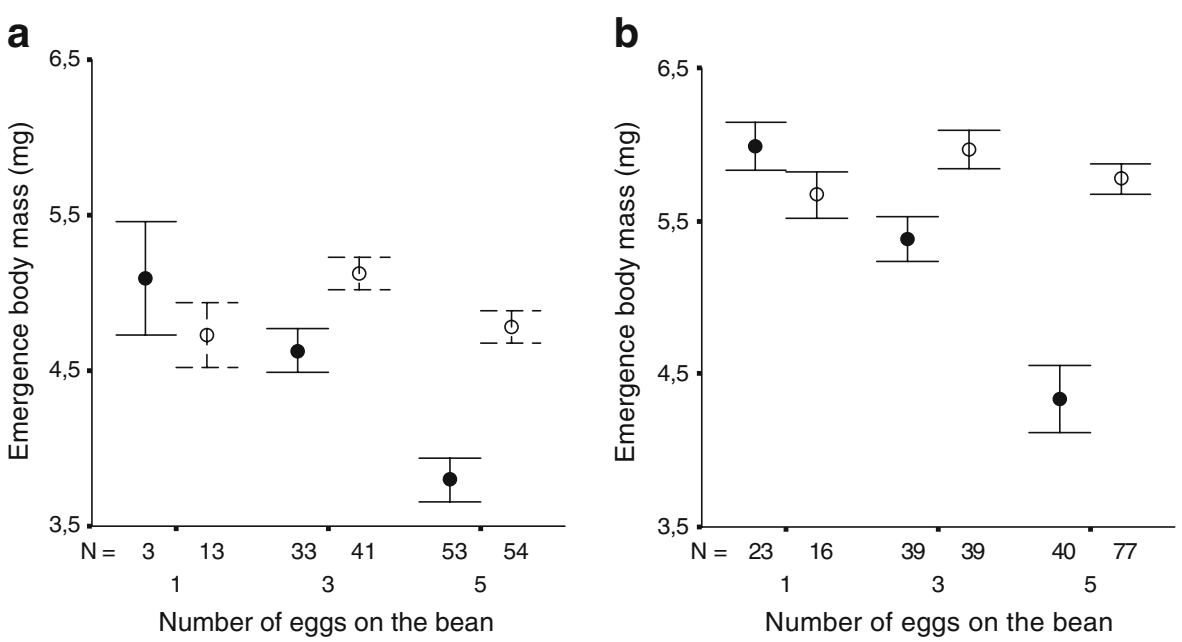

Fig. 2 Mean \pm SE emergence body mass of (a) male and (b) female beetles in relation to the number of eggs on the bean (one, three or five) and bean type (solid dot= mung bean, open dot = black-eye bean).

The pattern was identical with pronotum width. The sex effect on emergence mass and on pronotum width simply indicates that $C$. maculatus females are larger than males.

To estimate the effect of larval density on the relative emergence mass of the beetles, we conducted an analysis of covariance on emergence mass, in which we entered pronotum width as a covariate. From the potentially rather complex model (four interacting terms) we stepwise removed all non-significant interactions starting from the highest order interactions. The final model is presented in Table 5. There were two significant interactions including the covariate; one between bean type and pronotum width, showing that on mung beans beetles gain weight faster with increasing size than on black-eye beans (Fig. 3). However, the effect arises from the fact that on mung beans smaller beetles are lighter than on black-eye beans, and the significant main effect of bean type indicates that the relative emergence mass of beetles is greater on black eye-beans. The other interaction including the covariate was between sex and pronotum width showing that females gain weight faster with increasing size than males (Fig. 4). In addition, there was an interaction between bean type and sex as well as between bean type and number of eggs per bean (Table 5). The former interaction is

Table 5 Analysis of Covariance on Emergence Body Mass

\begin{tabular}{lrrrrr}
\hline Source & \multicolumn{1}{c}{$S S$} & d.f. & $M S$ & \multicolumn{1}{c}{$F$} & \multicolumn{1}{c}{$P$} \\
\hline Pronotum width & 208.03 & 1 & 208.03 & 794.93 & $<0.001$ \\
Sex & 1.74 & 1 & 1.74 & 6.64 & 0.010 \\
Bean type & 4.54 & 1 & 4.54 & 17.33 & $<0.001$ \\
Number of eggs & 1.98 & 2 & 0.99 & 3.79 & 0.023 \\
Bean type $\times$ number of eggs & 2.62 & 2 & 1.31 & 5.00 & 0.007 \\
Bean type $\times$ sex & 2.22 & 1 & 2.22 & 8.49 & 0.004 \\
Bean type $\times$ pronotum width & 4.21 & 1 & 4.21 & 16.09 & $<0.001$ \\
Sex $\times$ pronotum width & 2.84 & 1 & 2.84 & 10.87 & 0.001 \\
Error & 109.65 & 419 & 0.26 & & \\
\hline
\end{tabular}


Fig. 3 Emergence mass of beetles in relation to their pronotum width depending on the bean type. (solid dot/line = mung bean, open dot/broken line $=$ black-eye bean).

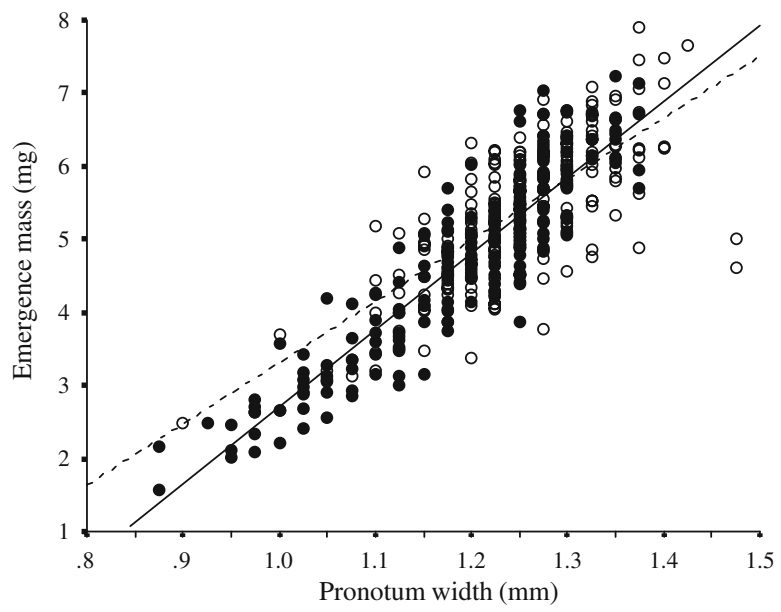

depicted in Fig. 5, and shows that for a given size, females gain more mass in blackeye beans than in mung beans while there is no such difference in males. The latter interaction follows the pattern already described for emergence mass: in mung beans the relative emergence mass was decreasing with increasing larval density but in black-eye beans larval density did not affect the relative emergence mass.

\section{Development Time and Longevity}

Population parameters on the development time of beetles are presented in Table 6. We began the analysis with a fully saturated model and continued by stepwise removal of all non-significant interaction terms starting from the highest order interactions. The final model consisted only main effects (Table 7). Larval density did not have an effect on development time (Table 7, Fig. 6). However, development time was longer in black-eye beans than in mung beans (Fig. 6) and there was again a clear sex effect: females needed longer development time than males (Table 7, Fig. 6).

Fig. 4 Emergence mass of beetles in relation to their pronotum width depending on the sex. (solid dot/line = males, open dot/ broken line $=$ females).

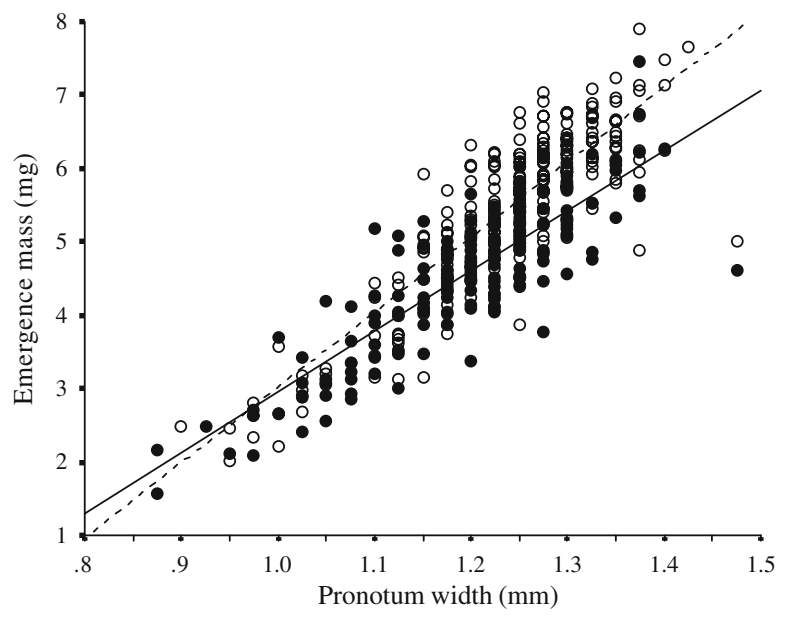


Fig. 5 Size corrected emergence mass (residual) of males and females in relation to the bean type. (solid dot/line $=$ mung bean, open dot/broken line $=$ black-eye bean).

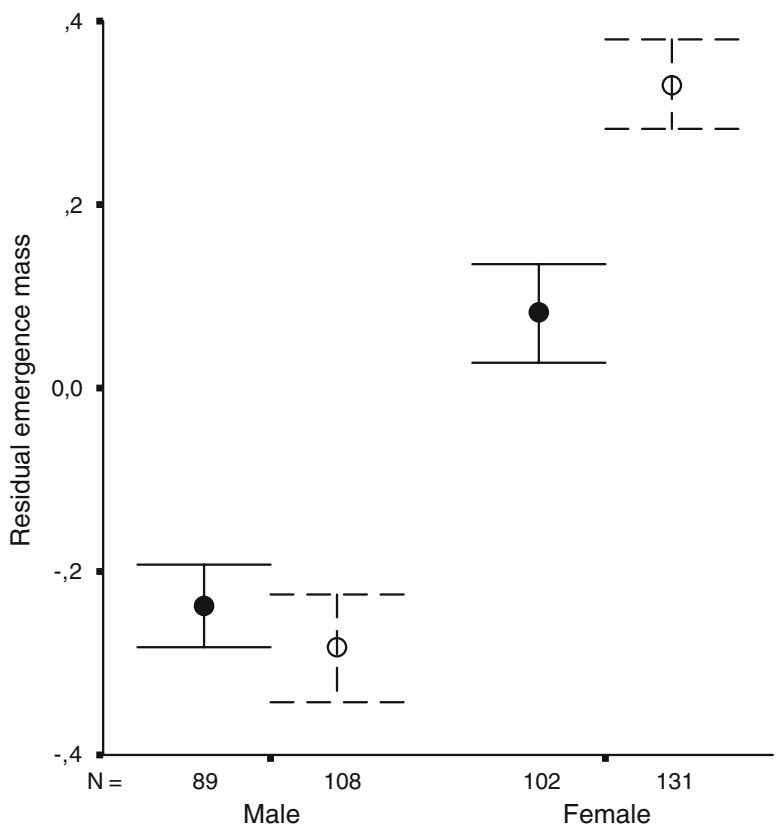

Population parameters on the longevity of beetles are presented in Table 8 . We conducted an analysis of covariance on the longevity, in which we entered pronotum width as a covariate. From the potentially rather complex model we again stepwise removed all non-significant interactions starting from the highest order interactions. Finally we ended with a model presented in Table 9 . Neither the larval density nor sex had an effect on longevity. However, the body size and the bean type had an effect: larger beetles and beetles raised on black eye-beans lived longer (Fig. 7). Interestingly, the correlation between emergence mass and longevity got stronger with increasing larval density (Spearman rank correlation of the correlation coefficient in Table 10 in relation to larval density (one, three or five eggs per bean); $r_{\mathrm{s}}=0.739, N=12, P=0.007$, Table 10).

\section{Larval Mortality and Sex Ratio}

Both bean type and number of eggs per bean had an independent effect on the proportion of surviving larvae (Logistic regression, Likelihood ratio test, $\chi_{3}^{2}=19.92$,

Table 6 Population Parameters on Development Time (Days)

\begin{tabular}{|c|c|c|c|c|c|c|c|c|}
\hline \multirow[t]{3}{*}{ No. of eggs } & \multicolumn{4}{|l|}{ Males } & \multicolumn{4}{|c|}{ Females } \\
\hline & \multicolumn{2}{|l|}{ Mung } & \multicolumn{2}{|c|}{ Black-eye } & \multicolumn{2}{|l|}{ Mung } & \multicolumn{2}{|c|}{ Black-eye } \\
\hline & Mean & SD & Mean & $\mathrm{SD}$ & Mean & $\mathrm{SD}$ & Mean & $\mathrm{SD}$ \\
\hline 1 & 47.0 & 1.73 & 46.2 & 5.05 & 47.4 & 3.03 & 48.8 & 7.45 \\
\hline 3 & 46.9 & 2.37 & 47.9 & 2.72 & 47.2 & 3.11 & 49.1 & 3.62 \\
\hline 5 & 47.2 & 2.51 & 48.0 & 4.00 & 47.3 & 3.01 & 49.4 & 5.22 \\
\hline
\end{tabular}


Table 7 Analysis of Variance on Development Time

\begin{tabular}{|c|c|c|c|c|c|}
\hline Source & $S S$ & d.f. & $M S$ & $F$ & $P$ \\
\hline Sex & 100.16 & 1 & 100.16 & 6.68 & 0.010 \\
\hline Bean type & 182.38 & 1 & 182.38 & 12.16 & 0.001 \\
\hline Number of eggs & 28.32 & 2 & 14.16 & 0.94 & 0.390 \\
\hline Error & 6357.76 & 424 & 15.00 & & \\
\hline
\end{tabular}

$P<0.001$; bean type: Wald $1=13.32, P<0.001$; number of eggs per bean: Wald ${ }_{2}=$ 6.37, $P=0.041$ ). Proportion of emerging larvae was higher in black-eye beans than in mung beans (Fig. 8). Larval mortality was higher in high larval density than in low larval density or in single-egg beans in mung beans (Fig. 8).

Finally, we analysed the sex of the emerged beetles in relation to the larval density and to our surprise found a strong bias towards females in mung beans that had only one egg on them $\left(\chi^{2}\right.$-test, $\chi^{2}{ }_{1}=15.39, P<0.001$; Fig. 9) and in black-eye beans that had five eggs on them $\left(\chi^{2}\right.$-test, $\left.\chi^{2}{ }_{1}=4.04, P=0.044\right)$. However, in all other cases the proportions of sexes were equal $\left(\chi^{2}\right.$-test, $\left.\chi_{1}^{2}<1.82, P>0.178\right)$.

\section{Adaptive Sex-ratio Manipulation by Females}

Because the sex-ratio bias in the larval density experiment emerged from an analysis that was not pre-planned, we conducted a formal experiment on sex-ratio bias to verify the result. Although the result in mung beans under no perceived larval density was in the same direction and tended towards female biased sex-ratio, it was not however significant ( $\chi^{2}$-test; mung bean 1st egg: $\chi_{1}^{2}=2.81, P=0.094$, Fig. 10). In all other cases the proportion of sexes were equal $\left(\chi^{2}\right.$-test, $\left.\chi_{1}^{2}<0.97, P>0.326\right)$.

a

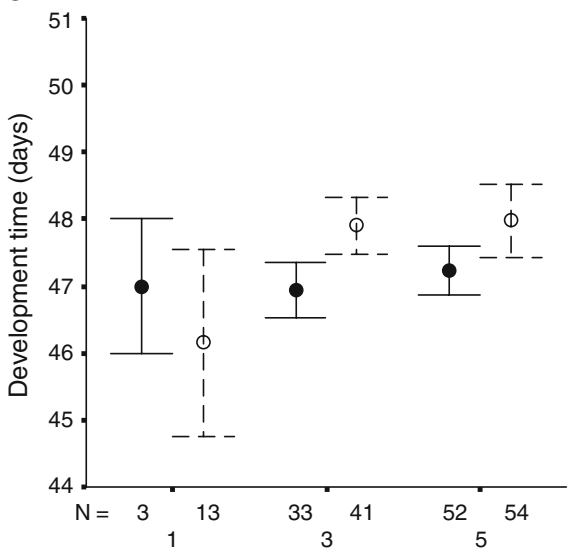

Number of eggs on the bean

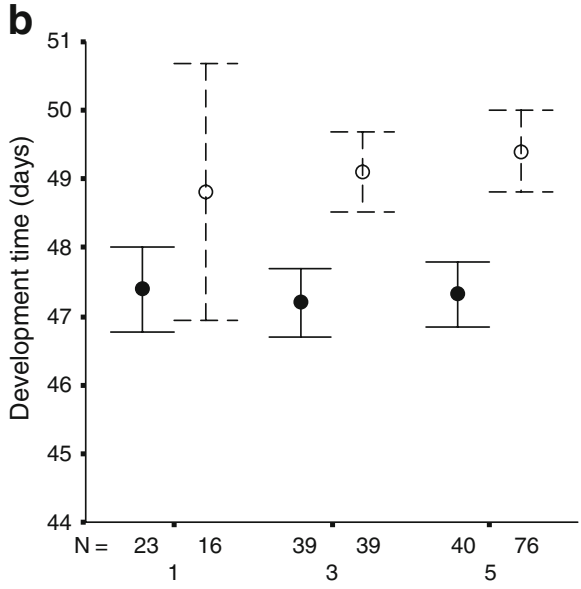

Number of eggs on the bean

Fig. 6 Mean \pm SE development time of (a) male and (b) female beetles in relation to the number of eggs on the bean (one, three or five) and bean type (solid dot = mung bean, open dot = black-eye bean). 
Table 8 Population Parameters On Longevity (Days)

\begin{tabular}{|c|c|c|c|c|c|c|c|c|}
\hline \multirow[t]{3}{*}{ No. of eggs } & \multicolumn{4}{|l|}{ Males } & \multicolumn{4}{|c|}{ Females } \\
\hline & \multicolumn{2}{|l|}{ Mung } & \multicolumn{2}{|c|}{ Black-eye } & \multicolumn{2}{|l|}{ Mung } & \multicolumn{2}{|c|}{ Black-eye } \\
\hline & Mean & $\mathrm{SD}$ & Mean & $\mathrm{SD}$ & Mean & $\mathrm{SD}$ & Mean & $\mathrm{SD}$ \\
\hline 1 & 21.7 & 5.13 & 24.6 & 4.31 & 27.2 & 4.56 & 26.1 & 6.90 \\
\hline 3 & 24.3 & 5.43 & 25.2 & 5.62 & 26.3 & 6.70 & 23.9 & 5.30 \\
\hline 5 & 24.2 & 3.44 & 23.4 & 5.31 & 24.7 & 5.60 & 25.6 & 7.37 \\
\hline
\end{tabular}

\section{Discussion}

We investigated female reproductive decisions in three experiments, concentrating on oviposition decisions, and the effects of larval density and host species on offspring life-history. In the experiment on oviposition preference we found that females laid more eggs and more often on black-eye beans than on mung beans. Earlier choice experiments between bean species have found similar results showing that $C$. maculatus females usually prefer larger beans within bean species (Cope and Fox 2003) as well as between species (Kawecki and Mery 2003; but see also Messina 2004), even if host preference and population may have some influence on a female's decisions (Wasserman 1981; Kawecki and Mery 2003; Messina 2004). Population may also influence on female egg dispersion and lifespan differences (Messina and Karren 2003; Fox et al. 2004). Earlier studies have also indicated that females tend to lay their eggs in order to avoid high larval density (e.g. Messina 1989; Colegrave 1993; Horng 1997, but see: Mitchell 1990). However, in general preferences are not a straight-forward phenomenon to empirically verify. Most earlier studies have investigated oviposition preference simply by a choice trial or by comparing the number of eggs on different species of beans (e.g. Guedes et al. 2003; Kawecki and Mery 2003; but see: Wasserman 1981; Messina and Mitchell 1989; Messina 2004). However, this approach does not account for the size of the beans, because by distributing eggs randomly on any bean surface, it will seem as if larger beans were favoured. Such a result emerges just because larger beans have larger surface area and thus just by chance get more hits. Therefore, we argue, that the analysis of oviposition preference should be made against the null hypothesis that females lay eggs randomly on beans in proportion to the surface area of the beans. Indeed, when we calculated our data per unit surface area, the number of eggs per surface area was not higher in black-eye beans. Moreover,

Table 9 Analysis of Covariance on Adult Longevity

\begin{tabular}{lrrrrr}
\hline Source & \multicolumn{1}{c}{$S S$} & d.f. & \multicolumn{1}{c}{$M S$} & \multicolumn{1}{c}{$F$} & $P$ \\
\hline Pronotum width & 789.40 & 1 & 789.40 & 25.28 & $<0.001$ \\
Sex & 19.34 & 1 & 19.34 & 0.62 & 0.432 \\
Bean type & 175.88 & 1 & 175.88 & 5.63 & 0.018 \\
Number of eggs & 21.67 & 2 & 10.83 & 0.35 & 0.707 \\
Error & 13019.34 & 417 & 31.22 & & \\
\hline
\end{tabular}



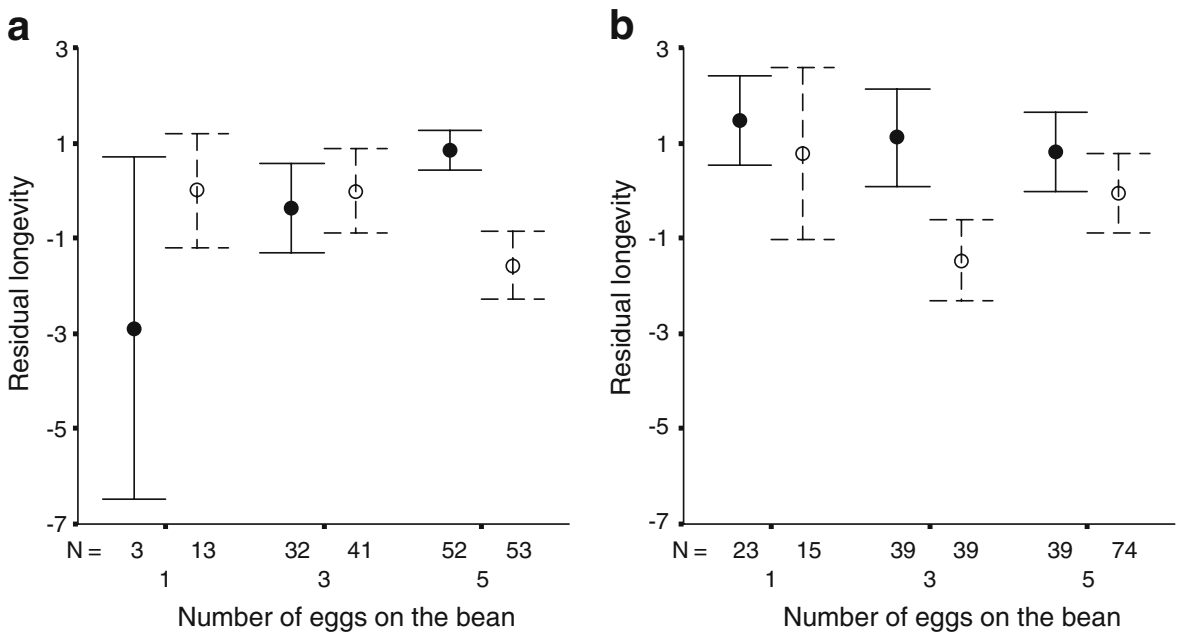

Fig. 7 Mean \pm SE size corrected longevity of (a) male and (b) female beetles in relation to the number of eggs on the bean (one, three or five) and bean type (solid dot = mung bean, open dot = black-eye bean).

the distribution of eggs on both bean types did not differ from a Poisson distribution but did differ from a uniform distribution. This pattern is consistent with females laying their eggs at random on beans rather than distributing them evenly across the available beans. One would expect to see a uniform distribution of eggs on available beans if females were actively avoiding high larval density in their oviposition preferences. However, there was a significant difference in the distribution of eggs between the bean types, suggesting that females may still make some minor oviposition decisions depending on the bean type.

Factors that could cause evolution of reproductive decisions in this species include the potentially negative effects of high larval density (e.g. Colegrave 1993) or variance in the suitability of the larval food resource. In C. maculatus the latter may be of some importance since the beetle collects all of its energy reserves during the larval stage (e.g. Fox and Tatar 1994) and adults do not need any nutrition or water to live and reproduce. We found clear interaction effects between larval density and bean type on emergence mass, pronotum width and relative mass (see also: Vamosi 2005). Under high larval density beetles had greater emergence mass,

Table 10 Correlation Between Emergence Mass and Longevity in Different Groups

\begin{tabular}{|c|c|c|c|c|c|c|}
\hline \multirow[t]{2}{*}{ No. of eggs } & \multicolumn{3}{|l|}{ Males } & \multicolumn{3}{|l|}{ Females } \\
\hline & $r$ & $N$ & $P$ & $r$ & $N$ & $P$ \\
\hline \multicolumn{7}{|l|}{ Mung } \\
\hline 1 & -0.997 & 3 & 0.052 & 0.331 & 23 & 0.331 \\
\hline 3 & 0.381 & 33 & 0.032 & 0.444 & 39 & 0.005 \\
\hline 5 & 0.502 & 52 & $<0.001$ & 0.465 & 40 & 0.003 \\
\hline \multicolumn{7}{|l|}{ Black-eye } \\
\hline 1 & 0.334 & 13 & 0.264 & 0.164 & 16 & 0.559 \\
\hline 3 & 0.239 & 41 & 0.132 & 0.049 & 39 & 0.766 \\
\hline 5 & 0.434 & 53 & 0.001 & 0.427 & 74 & $<0.001$ \\
\hline
\end{tabular}


Fig. 8 Mean \pm SE proportion of emerged from all eggs in one, three or five eggs on bean. (solid $d o t=$ mung bean, open dot $=$ black-eye bean).

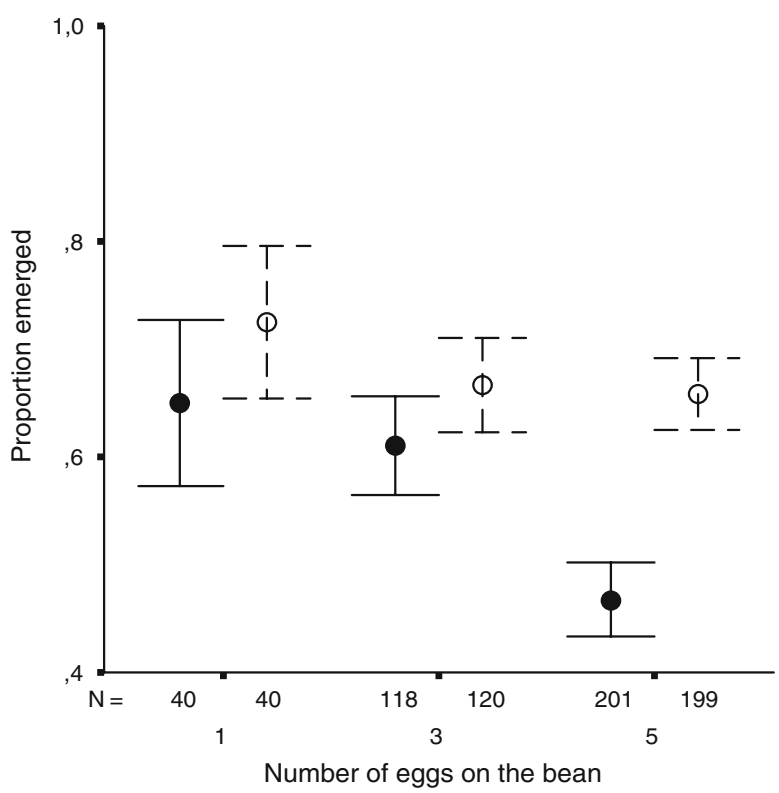

wider pronotum and greater relative mass on black-eye beans than on mung beans. In addition, development time was longer, larval mortality smaller and adult survival higher in black-eye beans. Thus, it is clear that there are benefits that females might obtain by favouring black-eye beans over mung beans.

In the larval density experiment, we found a strong sex-ratio bias in relation to number of eggs per bean and quality of beans. In mung beans with single egg (mung beans are the smaller bean type), there existed a strong female bias. Larval density affects the size of the beetles and the size has different consequence on female and male fitness. Female fitness is dependent on her fecundity which is directly dependent on her

a

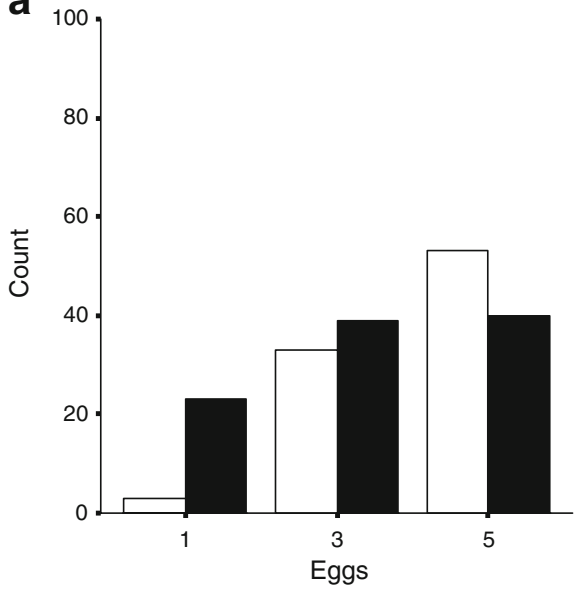

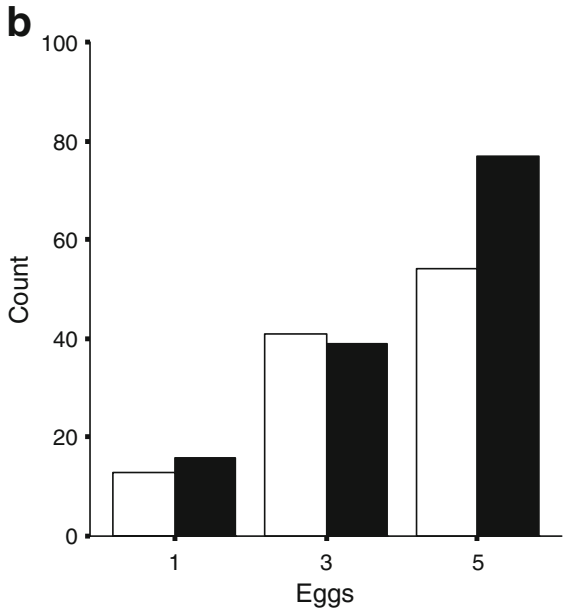

Fig. 9 Number of emerged males (white bars) and females (black bars) in (a) mung and (b) black-eye beans. 

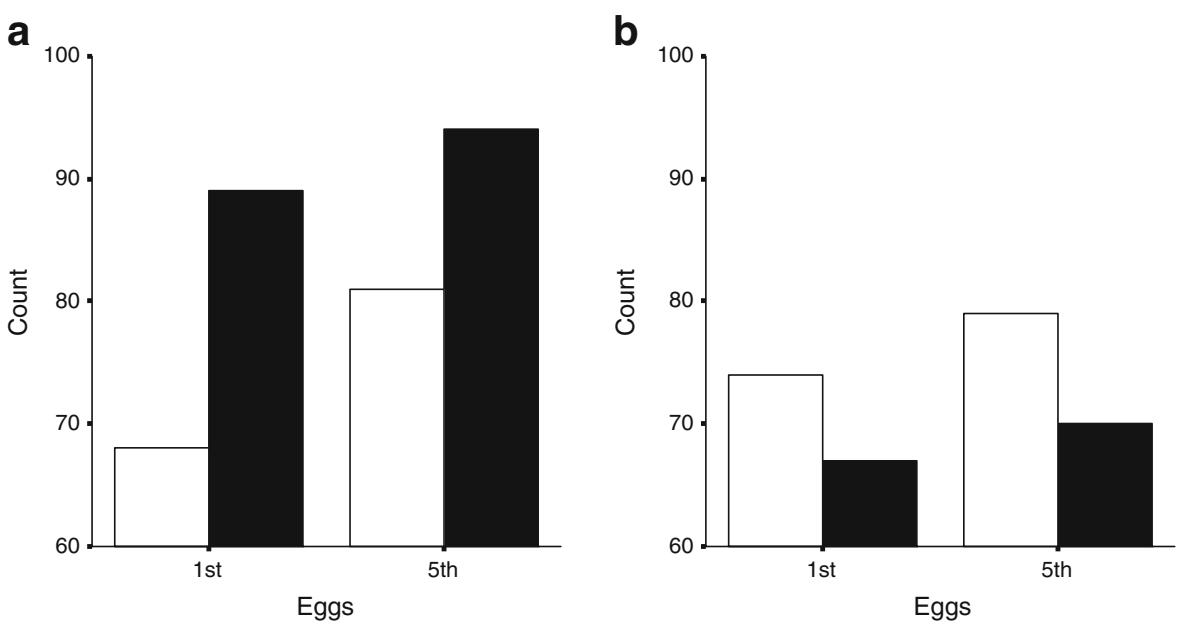

Fig. 10 Number of emerged males (white bars) and females (black bars) in (a) mung and (b) black-eye beans.

size (Colegrave 1993), while male size is not so directly linked to his reproductive success. The above result is consistent with a hypothesis that females might be making adaptive sex determination of their offspring depending on the predicted larval density. However, as this was not a pre-planned comparison we conducted a formal experiment to verify this observation. In this larger experiment we found no significant sex-ratio bias although the result still tended to be in the same direction i.e. that females laid more female eggs on unoccupied mung beans.

We detected an intriguing effect of an increasing correlation between pronotum width and longevity as the larval density increased. This suggests that the genetic ability to collect resources as a larva is increasingly exposed by larval density. We have shown elsewhere (Paukku et al. unpublished data) that there is a strong positive genetic correlation between body size and longevity in these beetles. So it seems that larval density increasingly exposes the genetic relationship between these traits, but that the relationship is blurred when beetles develop in an environment that has super-abundant resources. This is very interesting because we can draw a parallel between this finding and the core question in the field of sexual selection: it seems that stress over resource acquisition exposes the differences in genetic quality, and genetic quality is what females are selecting for in their preferences for costly male ornaments. Thus, it suggests that female preferences could be more rewarding in harsh environmental conditions (see e.g. Kotiaho et al. 2001).

We conclude that under high larval density and variable resources there is clear evidence that reproductive decisions by females can have significant effects on offspring fitness. By choosing black-eye beans over mung beans females will produce offspring that are larger, relatively heavier and live longer and thus are likely to have higher fitness. However, our data suggest that females use a random placement of eggs which by chance alone results in more eggs on beans that are larger and where there are more resources for competing larvae. To unequivocally determine whether females make further adaptive decisions to capitalise on the benefits of avoiding high larval density requires further experimentation. 
Acknowledgments We thank Erna Suutari, Katja Tynkkynen, Otto Seppälä, Anssi Laurila, Raine Kortet and Joseph Leopold Tomkins for valuable comments to this work. We thank Daniele Pennese, Kari Lahtinen and Leena Ketola for assistance in animal handling and measuring. This study was funded by the Academy of Finland and the Centre of Excellence for Evolutionary Research.

Open Access This article is distributed under the terms of the Creative Commons Attribution Noncommercial License which permits any noncommercial use, distribution, and reproduction in any medium, provided the original author(s) and source are credited.

\section{References}

Agnew P, Haussy C, Michalakis Y (2000) Effects of density and larval competition on selected life history traits of Culex pipiens quinquefasciatus (Diptera: Culicidae). J Med Entomol 37:732-735

Bell G, Koufopanou V (1986) The cost of reproduction. In: Dawkins R, Ridley M (eds) Oxford surveys in evolutionary biology. Oxford University Press, Oxford, pp 83-131

Clutton-Brock T (1991) The evolution of parental care. Princeton University Press, Princeton, New Jersey

Colegrave N (1993) Does larval competition affect fecundity independently of its effect on adult weight? Ecol Entomol 18:275-277

Cope JM, Fox CW (2003) Oviposition decisions in the seed beetle, Callosobruchus maculatus (Coleoptera: Bruchidae): effects of seed size on superparasitism. J Stored Prod Res 39:355-365

Faraji F, Janssen A, Sabelis MW (2002) The benefits of clustering eggs: the role of egg predation and larval cannibalism in a predatory mite. Oecologia 131:20-26

Fox CW (1993) Multiple mating, lifetime fecundity and female mortality of the bruchid beetle, Callosobruchus maculatus (Coleoptera: Bruchidae). Funct Ecol 7:203-208

Fox CW, Tatar M (1994) Oviposition substrate affects adult mortality, independent of reproduction, in the seed beetle Callosobruchus maculatus. Ecol Entomol 19:108-110

Fox CW, Czesak ME, Wallin WG (2004) Complex genetic architecture of population differences in adult lifespan of a beetle: nonadditive inheritance, gender differences, body size and a large maternal effect. J Evol Biol 17:1007-1017

Guedes RNC, Smith RH, Guedes NMP (2003) Host suitability, respriration rate and the outcome of larval competition in strains of the cowpea weevil, Callosobruchus maculatus. Physiol Entomol 9:191-196

Gullan PJ, Cranston PS (2000) The insects - an outline of entomology. Blackwell Science, California

Horng S-B (1997) Larval competition and egg-laying decisions by the bean weevil Callosobruchus maculatus. Anim Behav 53:1-12

Hunt J, Simmons LW, Kotiaho JS (2002) A cost of maternal care in the dung beetle Onthophagus taurus? J Evol Biol 15:57-64

Janz N, Bergström A, Sjögren A (2005) The role of nectar sources for oviposition decisions of the common blue butterfly Polyommatus icarus. Oikos 109:535-538

Kawecki TJ, Mery F (2003) Evolutionary conservatism of geographic variation in host preference in Callosobruchus maculatus. Ecol Entomol 28:449-456

Komdeur J (2003) Daughters on request: about helpers and egg sexes in the Seychelles warbler. Proc R Soc Lond B 270:3-11

Kotiaho JS (2001) Costs of sexual traits: a mismatch between theoretical considerations and empirical evidence. Biol Rev 76:365-376

Kotiaho JS, Simmons LW, Tomkins JL (2001) Towards a resolution of the lek paradox. Nature 410:684-686 Krebs JR, Davies NB (1997) An introduction to behavioural ecology, 3rd edn. Blackwell Science, Oxford Messina FJ (1989) Genetic basis of variable oviposition behavior in Callosobruchus maculatus (Coleoptera: Bruchidae). Ann Entomol Soc Am 82:792-796

Messina FJ, Mitchell R (1989) Intraspecific variation in the egg-spacing behavior of the seed beetle Callosobruchus maculatus. J Insect Behav 6:727-742

Messina FJ, Karren ME (2003) Adaptation to a novel host modifies host discrimination by the seed beetle Callosobruchus maculatus. Anim Behav 65:501-507

Messina FJ (2004) How labile are the egg-laying preferences of seed beetles? Ecol Entomol 291:318-326

Mitchell R (1990) Behavioral ecology of Callosobruchus maculatus. In: Fujii K, Gatehouse MR, Johnson CD, Mitchell R, Yoshida T (eds) Bruchids and legumes: Economics, ecology and eoevolution. Kluwer Academic, Netherlands, pp 317-330 
Partridge L, Harvey PH (1985) Costs of reproduction. Nature 316:20

Paukku S, Kotiaho JS (2005) Cost of reproduction in Callosobruchus maculatus: effects of mating on male longevity and the effect of male mating status on female longevity. J Insect Physiol 51:1220-1226

Sherratt TN, Church SC (1994) Ovipositional preferences and larval cannibalism in the Neotropical mosquito Trichoprosopon digitatum (Diptera: Culicidae). Anim Behav 48:645-652

Stouthamer R, van Tilborg M, de Jong JH, Nunney L, Luck RF (2001) Selfish element maintains sex in natural populations of a parasitoid wasp. Proc R Soc Lond B 268:617-622

Trivers RL (1972) Parental investment and sexual selection. In: Campbell B (ed) Sexual selection and the descent of man. Aldine, Chicago, pp 136-179

Tomkins JL, Simmons LW, Alcock J (2001) Brood provisioning strategies in Dawson's burrowing bee, Amegilla dawsoni (Hymenoptera: Anthophorini). Behav Ecol Sociobiol 50:81-89

Vamosi SM (2005) Interactive effects of larval host and competition on adult fitness: an experimental test with seed beetles (Coleoptera: Bruchidae). Funct Ecol 19:859-864

Wasserman SS (1981) Genetic variation in adaptation to foodplants among populations of the southern cowpea weevil, Callosobruchus maculatus: evolution of oviposition preference. Entomol Exp Appl 42:201-212

Williams GC (1966) Natural selection, the cost of reproduction, and a refinement of Lack's principle. Am Nat 100:687-690 